\title{
Asia-Pacific Journal of Health, Sport and Physical Education
}

\section{Socialisation and learning to teach using the teaching personal and social responsibility approach}

\section{K. Andrew R. Richards \& Barrie Gordon}

To cite this article: K. Andrew R. Richards \& Barrie Gordon (2017) Socialisation and learning to teach using the teaching personal and social responsibility approach, Asia-Pacific Journal of Health, Sport and Physical Education, 8:1, 19-38, DOI: 10.1080/18377122.2016.1272424

To link to this article: https://doi.org/10.1080/18377122.2016.1272424

\section{Published online: 27 Dec 2016.}

Submit your article to this journal $\pi$

Џ Article views: 612

Q View related articles ¿

View Crossmark data

Citing articles: 8 View citing articles $\widetilde{ }$ 


\title{
Socialisation and learning to teach using the teaching personal and social responsibility approach
}

\author{
K. Andrew R. Richards ${ }^{\mathrm{a}}$ and Barrie Gordon ${ }^{\mathrm{b}}$

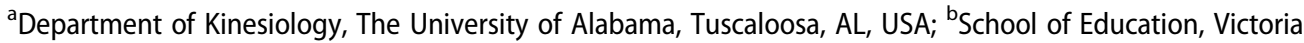 \\ University of Wellington, Wellington, New Zealand
}

\begin{abstract}
Occupational socialisation theory (OST) is a dialectical approach to understanding teachers' recruitment, training, and lived experiences in school settings. Research using this model has shown that socialisation influences how physical educators interpret or 'read' pedagogical models. However, this research has not been extended to the teaching personal and social responsibility (TPSR) model, which differs from other models in its concurrent focus on responsibility and physical activity outcomes. This study, therefore, sought to understand how physical educators learned to use the model in light of current and prior socialisation. Participants included eight physical education teachers (five females, three males) from two schools in New Zealand. Data collection included four individual interviews with each teacher and systematic and ethnographic observations of teaching. Results indicated that prior socialisation and influences within the current school influenced fidelity to the TPSR model. Social support and alignment of the model with other school initiatives supported implementation, whereas a lack of clarity and competing priorities reduced fidelity. Results are discussed in relation to OST, and future directions for research are proposed.
\end{abstract}

\section{ARTICLE HISTORY}

Received 25 May 2016

Accepted 6 December 2016

\section{KEYWORDS}

Teaching personal and social responsibility; school context; model fidelity; occupational socialisation theory

Occupational socialisation theory (OST; Richards, Templin, \& Graber, 2014; Templin \& Schempp, 1989) has been used as a framework for studying the recruitment, training, and career-long socialisation of physical education (PE) for nearly 40 years. During this time, teachers' backgrounds and biographies have been found to play an important role in the development of subjective theories or personal understandings of PE (Grotjahn, 1991; Richards et al., 2014). New socialisation experiences that align with individuals' subjective theories are incorporated into their worldview, while inconsistent information is filtered out. PE teachers now employ a variety of curricular and instructional models (also referred to as pedagogical models; Kirk, 2013), in their teaching and model-based instruction has become a focal point in many physical education teacher education (PETE) programs (Lund \& Tannehill, 2010; Metzler, 2011). Previous research has illustrated that preservice and inservice teachers' subjective theories play an important role in understanding how they interpret or 'read' (Gore, 1990) these models, including sport education (Curtner-Smith, Hastie, \& Kinchin, 2008), adventure education 
(Zmudy, Curtner-Smith, \& Steffen, 2009), and teaching games for understanding (Vollmer \& Curtner-Smith, 2016). However, less is known about the ways in which socialisation experiences influence PE teachers' interpretation of other pedagogical models, including teaching personal and social responsibility (TPSR; Hellison, 2011). Developing this understanding is essential to researchers and practitioners concerned with developing high-quality TPSR programs because one's reading of the modelling has the potential influence their delivery of it, which has implications related to fidelity of model implementation. This is particularly relevant to TPSR given that it has strong affective domain goals, which differentiates it from many other approaches to teaching PE.

\section{The TPSR model}

The TPSR model (see Hellison, 2011 for a full overview of the model) is recognised as a high-quality pedagogical model, and is referenced in most PE curriculum texts (Lund \& Tannehill, 2010; Metzler, 2011). It is a student-centred pedagogical approach that seeks to use the attraction of physical activity contexts to foster personal and social responsibility (Hellison, 2011). This emphasis does not negate the importance of PE curriculum outcomes, with an expectation that goals related to both affective development and PE curriculum will be achieved (Hellison, 2011). TPSR has four major goals; that participants become more respectful, involved, caring of others, and self-directed learners. While achieving these goals within PE is important, the intention is that they will be transferred outside the classroom into other areas of life (Gordon \& Doyle, 2015; Hellison, 2011).

While applications of TPSR have traditionally focused on after-school or communitybased programs (Hellison, 2011), there has been increased research interest in TPSR when implemented in school-based PE over the last decade (e.g. Hemphill, Templin, \& Wright, 2015; Jung \& Wright, 2012; Lee \& Choi, 2015). Evidence indicates that appropriate applications of the model can foster a positive learning environment and impact student behaviour (Wright \& Burton, 2008), develop conflict resolution skill and respect for others (Escarti, Gutierrez, Pascual, \& Llopis, 2010), and foster a better understanding of personal and social responsibility (Gordon, 2010). Further, some research has noted success in helping PE teachers learn to implement the TPSR approach through ongoing and sustained professional development (Escarti et al., 2010; Hemphill, Templin, et al., 2015). However, as is true of models-based practice more generally (Casey, 2014), it has also been acknowledged that additional work is needed to understand how teachers learn to implement the TPSR model (Martinek \& Hellison, 2009), and the extent to which they implement it as intended (Wright, 2009). In the current study we sought to understand the role of occupational socialisation on their 'reading' of the TPSR model when learned through a continuing professional development (CPD) initiative.

\section{Overview of OST}

While OST has been used to understand PE teacher socialisation for nearly 40 years (Templin \& Richards, 2014), it and other intergenerational models for the transmission of beliefs and behaviours have been criticised by those noting that PE does not operate in isolation from broader social and cultural institutions that influence understandings of gender, ethnicity, and sexuality, among other things (Tinning, 2004). As a result, 
some authors have turned to theoretical perspectives rooted in the writings of Giddens (e.g. Cassidy \& Tinning, 2004; O’Connor \& Macdonald, 2002), Bourdieu (e.g. Brown, 2005; lisahunter, 2004), and Foucault (e.g. Larsson, 2014; Wright, 2002) in efforts to understand teachers identity formation and the influence of social factors within and beyond PE. While these critiques are important, OST remains a viable and widely adopted lens through which to view the recruitment, training, and ongoing socialisation of PE teachers, as is captured in multiple recent review articles (e.g. Pike \& Fletcher, 2014; Richards et al., 2014; Templin \& Richards, 2014) and the publication of a new book focused on PE teacher socialisation (Richards \& Gaudreault, 2017).

The OST framework examines 'all kinds of socialisation that initially influence persons to enter the field of PE and later are responsible for their perceptions and actions as teacher educators and teachers' (Lawson, 1986, p. 107). The perspective has been described as dialectical because, in contrast to structural-functionalist models of socialisation, scholars using OST recognise social actors' sense of agency in their ability to resist the influence of individuals and social structures that seek to socialise them. As such, the socialisation process is viewed as a 'a contest of social thesis against individual antithesis' in which both the teacher and socialising agents are subject to change (Schempp \& Graber, 1992, p. 331). Influences that socialise individuals into and through careers in PE are typically described along a temporal continuum, which includes acculturation, professional socialisation, and organisational socialisation. Experiences across these phases of socialisation influence the ways in which PE teachers 'read' and implement pedagogical models in practice (CurtnerSmith et al., 2008).

Acculturation examines the ways in which individuals are socialised into careers in $\mathrm{PE}$ through interactions with parents, teachers, coaches, and counselors while they are still school-aged children and adolescents (Valtonen, Reunamo, Hirvensalo, \& Ruismäki, 2015). Enjoyment of sport and physical activity, positive experiences participating in school PE, and an interest in working with young people have been cited as factors that facilitate entry into the profession (Curtner-Smith, 2001; Curtner-Smith et al., 2008; Curtner-Smith \& Sofo, 2004). This pre-training socialisation leads to the formation of subjective theories (Grotjahn, 1991) related to the purposes and goals of PE, which can be difficult to change through formal teacher training (Richards, Templin, \& Gaudreault, 2013). Most recruits, however, do not have full insight into the technical aspects of teaching (e.g. lesson planning, assessment, and grading), which results in faulty or incomplete subjective theories (Richards et al., 2014).

Professional socialisation refers to PETE training, which typically occurs in a higher education setting. When recruits' subjective theories do not align with the messages espoused by PETE faculty, they may exercise their sense of agency and resist the socialisation process (Richards et al., 2014). Graber (1991) referred to this resistance as studentship and noted that, because PETE faculty hold a position of power over preservice teachers, it is often covert. Well-planned field experiences (Curtner-Smith \& Sofo, 2004), studentcentred pedagogies such as autobiographical essays and case studies (Hemphill, Richards, Gaudreault, \& Templin, 2015; Richards et al., 2013), a focus on reflective practice (Tsangaridou \& O’Sullivan, 1997), and a shared technical culture among faculty (Graber, 1996) are among the factors that contribute to effective preservice training.

Organisational socialisation occurs on the job and in the context of the schools (Van Maanen \& Schein, 1979). This phase of socialisation is ongoing and stretches from the 
time one enters the field through departure or retirement (Lynn \& Woods, 2010). Schools operate as custodial bureaucracies in which the status quo is maintained informally through the institutional press (Curtner-Smith et al., 2008) as veteran teachers and administrators attempt to perpetuate the prevailing norms of the institution. This can lead to the 'washout effect' as new teachers abandon practices learned during PETE to comply with institutional expectations (Blankenship \& Coleman, 2009). School environments that support PE, and where teachers and administrators embrace innovative practices learned through PETE, are more likely to result in smooth transitions into teaching (Richards et al., 2014; Stroot \& Ko, 2006).

\section{'Reading' pedagogical models}

Extrapolating from Gore's (1990) notion of 'pedagogy as text', Curtner-Smith et al. (2008) noted that different 'readings' or interpretations of pedagogical models were possible based on teachers' socialisation experiences. These different interpretations result in different deliveries of the model, which result in varying degrees of model fidelity. In one study of the sport education model, Curtner-Smith et al. (2008) found that beginning teachers delivered three different forms of sport education. The full version as intended, a watered down approach that includes only some of the model elements, and a cafeteria approach through which the teachers only select elements of the model that fit with their current approach to teaching. Further, the results of this study indicated that experiencing a quality PE program during acculturation, participating in an effective PETE experience that focused on sport education, and a supportive school culture led to implementation of the full or watered down approaches to the model. Low quality PE during acculturation, an ineffective PETE experience or one that did not emphasise sport education, and a school culture focus on maintenance of the status quo led to the cafeteria approach or no implementation at all. Similar findings have surfaced in studies related to adventure education (Zmudy et al., 2009) and teaching games for understanding (Vollmer \& Curtner-Smith, 2016), which reinforces the role that socialisation plays in teachers' reading and implementation of model-based instruction.

Previous research that has examined the implementation of TPSR-focused CPD has been mixed. Some evidence indicates that programing can be effective in increasing the extent to which teachers implement responsibility-focused strategies in their teaching (Beaudoin, 2012; Hemphill, Templin, et al., 2015). Other studies have, however, indicated that TPSR is not always implemented in accordance with the core principals of the model (Mrugala, 2002; Pascual et al., 2011), leading to some concern related to model fidelity (Wright, 2009). One potential explanation for the lack of fidelity is that prior research has often neglected to consider the socialisation experiences of teachers involved in CPD initiatives and how subjective theories (Grotjahn, 1991) developed through that socialisation influence the ways in which teachers 'read' (Gore, 1990) the TPSR model. Therefore, the purpose of this study was to examine the experiences of eight PE teachers involved in a long-term TPSR-based CPD initiative with a focus on these experiences in relation to their prior and ongoing socialisation. Research questions included: (1) how do the teachers implement the TPSR approach?, (2) how do teachers prior socialisation experiences influence their receptivity to TPSR? and (3) how do teachers describe facilitators and inhibitors of TPSR implementation? 


\section{Method}

\section{Participants and setting}

The CPD program involved eight full-time New Zealand High School PE teachers (five females, three males), four from each of two schools (see Table 1 for demographic information). High Tower High School was a coeducational school of 1160 students in a small North Island beachside community. Langston High School was a coeducational urban school of 914 students situated in the capital city of Wellington. The Heads of Department from each school, Fredrick and Ashley, were both participants in the CPD program. All but one teacher were experienced teachers of PE with the majority in mid-career (1020 years experience). Permission was received from the Victoria University Ethics Committee to complete this research.

\section{Overview of the professional development initiative}

The CPD program ran throughout a full teaching year and was based in the teachers' schools. Phase one involved a full day workshop for all eight teachers at High Tower. The second author, who is an experienced practitioner and researcher in the TPSR model, facilitated this workshop, which started with an introduction to the philosophical underpinnings, intended outcomes, and four major themes of TPSR. Following this introduction, the workshop examined how the model could look in practice with teachers participating in a series of practical activities that demonstrated the model being integrated into units of work. In line with Hemphill, Richards, et al.'s (2015) recommendation, the teachers were introduced to the Tool for Assessing Responsibility-based Education (TARE; Wright \& Craig, 2011), which is designed to enable an analysis of TPSR model fidelity. Teachers were then given an opportunity to practice using the TARE instrument while observing a class taught by a peer.

Phase two involved the implementation of a TPSR-focused CPD initiative that mirrored Hemphill, Richards, et al.'s (2015) recommendations. Teachers were paired up with a partner to work with over the year with the expectation that they would work together informally to help and support their developing understanding of TPSR. The second author visited all teachers within the first four weeks. At that time teachers were observed teaching a TPSR lesson by the researcher and their partner teacher using the TARE assessment. At the conclusion of the lesson both teachers and the researcher debriefed the lesson using the TARE results as the basis for discussion. The second

Table 1. Overview of participant demographic information.

\begin{tabular}{llll}
\hline Name & Gender & Teaching experience & School \\
\hline Frederick (HOD) & Male & Mid-career & High Tower \\
Alicia & Female & Mid-career & High Tower \\
Shelia & Female & Mid-career & High Tower \\
Harry & Male & Mid-career & High Tower \\
Ashley (HOD) & Male & Mid-career & Langston \\
Jessica & Female & Over 30 years & Langston \\
Daisy & Female & Two years & Langston \\
Cynthia & Female & Mid-career & Langston \\
\hline
\end{tabular}

Note: HOD = Head of Department. 
author continued to visit and observe teachers throughout the year on a monthly basis. These observations were followed by a discussion on the lesson and, when appropriate, suggestions for improvement. On two of these visits, at the middle and end of the year, TARE assessments were completed and used as a prompt for discussion with the teachers. The researcher also met with the four teachers, as a group, at the two schools on three occasions. These meetings were used to identify problems, offer suggestions, and share good practices. The CPD program was designed to be ongoing throughout the year and offer teachers both external support from the second author, and internal support from their peer teacher and other teachers in the department.

\section{Data collection}

\section{Individual interviews}

The primary source of data was semi-structured interviews with the participants (Patton, 2015). All eight teachers completed three individual interviews at the beginning, middle, and end of the yearlong CPD program. The interviews were completed at the teacher's school in a quiet office and took between 45 and 60 minutes. All interviews were allowed to continue until their natural conclusion. Six of the teachers subsequently completed a fourth interview one year after completion of the CPD initiative. Two teachers, Jessica and Daisy, were unavailable for participation in the follow-up interview due to personal situations. The purpose of the first three interviews was to understand how the teachers experienced the implementation of TPSR as well as the challenges and facilitators they encountered. Example interview questions included: 'what have you found to be the challenges involved with implementing TPSR into your program?' (interview one), 'what does TPSR look like in your class?' (interview two), and 'how confident do you feel in your knowledge of TPSR at this stage?' (interview three). The fourth interview sought to ascertain the degree to which the teachers were influenced by the CPD initiative a year after its completion and to query the teachers' socialisation experiences. Example interview questions for this interview were 'what kind of PE teaching did you have at your high school?' and 'how does TPSR work for different kinds of students in your classes?'

\section{Ethnographic observations}

The second author completed five or six observations of each teacher teaching TPSRbased PE lessons over the year. The observer arrived approximately 10 minutes before the class commenced and then observed the full 60-minute teaching period. During these observations he took ethnographic field notes (Patton, 2015) guided broadly by an interest in establishing how the teachers were implementing TPSR into their own practice, the students' responses to the model, and the culture of the class. Field notes were subsequently transcribed for inclusion in the dataset.

\section{Systematic observation of teaching}

In response to Wright (2009) and Hemphill, Richards, et al.'s (2015) recommendation that additional attention be paid to the implementation fidelity of the TPSR model, the second author completed three TARE (Wright \& Craig, 2011) assessments on each teacher over the year. While Hellison's (2011) conceptualisation of TPSR includes flexibility for 
teachers to implement the model to suit their setting, it is important that this flexibility does not progress into a toxic mutation whereby the name is retained, but the practice varies drastically from the model's intention (Gordon, Jacobs, \& Wright, 2016). Through direct observation and time sampling ratings in five-minute intervals, the TARE instrument evaluates teaching strategies (i.e. integration, transfer, empowerment, and relationships) and student behaviours (i.e. self-control, participation, effort, self-direction, and caring) viewed as integral to the implementation of TPSR (Hellison, 2011). Higher ratings on the TARE indicate that the model is being implemented with greater fidelity. The interrater reliability for the instrument has been documented through previous research and been found to range from 0.78 to 1.00 for each item (Wright \& Craig, 2011). Further, the second author, who conducted the TARE observations, was trained to use the instrument by the developers and is experienced in its use.

\section{Data analysis and trustworthiness}

The lead author used a combination of inductive and deductive analysis along with the constant comparative method to analyse the data. By combining inductive and deductive analysis the results could be interpreted through the lens of OST (i.e. deductive), but the researcher remained open to new insights that extended or challenged the theory (i.e. inductive; Patton, 2015). Through constant comparison, the results were formed and reformed throughout the data analysis process to account for the coding of new data (Glaser \& Strauss, 1967). As the data analysis process continued, coded data were grouped into themes (Patton, 2015). Once all of the data had been coded, the authors reviewed the themes and created a thematic structure that included themes and subthemes that communicated the participants' perspectives.

In conducting qualitative research trustworthiness is enhanced through methodological decisions that seek to enhance the quality of the study design (Lincoln \& Guba, 1985). In the current study, the researcher adopted the following strategies: data triangulation, member checks, peer debriefing, and the maintenance of an audit trail. Collecting data from multiple participants and multiple sources facilitated data triangulation. Member checks were built into the research design as interviews asked participants to reflect on comments they had made previously. The second author acted as a peer debriefer by reviewing the thematic structure and providing feedback that helped to identify the final themes. Finally, an audit trail was maintained through the collection and analysis of data to develop transparency through the research process.

\section{Results}

\section{Fidelity to the TPSR approach}

Fidelity to the TPSR model was examined both through systematic observations of taught lessons and through discussing implementation with the participations. The final TARE assessments completed on the teachers demonstrated a range of fidelity to the model in the reality of their practice (see Table 2). When considering the degree to which the four major themes were evident in the lessons it was found that the integration of TPSR into the physical activity section of the lesson, empowerment of students, and 
Table 2. Personal-social responsibility themes from TARE observations.

\begin{tabular}{lcccc}
\hline Teacher & Integration & Transfer & Empowerment & Relationships \\
\hline Ashley & 3 & 1 & 3 & 4 \\
Daisy & 2 & 0 & 1 & 2 \\
Jessica & 4 & 0 & 4 & 4 \\
Cynthia & 3 & 0 & 3 & 3 \\
Fredrick & 4 & 1 & 4 & 4 \\
Harry & 2 & 1 & 2 & 2 \\
Shelia & 4 & 2 & 4 & 4 \\
Alicia & 3 & 1 & 3 & 4 \\
\hline
\end{tabular}

Note: (0) never: throughout the entire lesson none of the teacher's words or actions clearly convey or align with this strategy, (1) rarely: not generally implemented into the teaching but may be reflected in some isolated words or actions on the teacher's part, (2) occasionally: some of the teachers' words and actions connect to this strategy either directly or indirectly during the lesson, (3) frequently: theme is addressed directly and evidenced at several points in the lesson through the words and actions of the teacher, (4) extensively: theme is seamlessly addressed and evidenced in multiple ways throughout the lesson through the words and actions of the teacher.

positive teacher-student relationships themes were all well established in the majority of teachers. The theme that was largely missing was transfer. Based on the TARE observations, six of the eight teachers were applying three of the themes either extensively (4) or frequently (3) with some attempts at transfer occasionally (2), rarely (1), or in two cases, never (0). Daisy and Harry, however, generally demonstrated little application of the themes in their practice. In relation to student behaviours (see Table 3), self-control, participation, and effort were generally high for all classes. Self-direction and caring, which could be considered more TPSR specific, were scored lower, although they were present at some level for all classes. It can be concluded that model fidelity was reasonable high, although there was variation both across TPSR themes and between individual teachers. Daisy and Harry implemented with less fidelity than the other teachers.

Interview data revealed that, as a result of their current and prior socialisation experiences, the teachers in this study self-reported varying levels of fidelity to TPSR. Several of the teachers discussed the importance of making a concentrated effort to be deliberate about implementation. They also, however, noted that at times they struggled reconciling the requirements of TPSR with some of the more traditional pedagogies they had become accustomed to using.

Table 3. Student responsibility themes from TARE observations.

\begin{tabular}{lccccc}
\hline Teacher & Self-control & Participation & Effort & Self-direction & Caring \\
\hline Ashley & 4 & 4 & 3 & 3 & 2 \\
Daisy & 3 & 3 & 2 & 2 & 3 \\
Jessica & 4 & 1 & 4 & 4 & 4 \\
Cynthia & 4 & 4 & 3 & 3 & 3 \\
Frederick & 3 & 4 & 3 & 3 & 2 \\
Harry & 3 & 3 & 3 & 2 & 2 \\
Shelia & 3 & 4 & 4 & 4 & 4 \\
Alicia & 3 & 4 & 4 & 3 & 3 \\
\hline
\end{tabular}

Note: Rating scale: (0) very weak: few if any students displayed this responsibility, (1) weak: some students displayed this responsibility, (2) moderate: many students displayed this responsibility but many did not, (3) strong: most students displayed this responsibility throughout the lesson with only minor and/or isolated exceptions, (4) very strong: all students displayed this responsibility throughout the lesson with no observed exceptions. 


\section{Being deliberate about implementation}

The majority of the teachers attempted to implement TPSR as intended through the CPD initiative. Shelia explained she changed her class in order to empower students and promote self-directed learning: 'students are teaching each other, assessing each other by having criteria for a certain skill and then actually observing each other, and then giving each other feedback'. In describing how his class had changed, Ashley noted that 'I would say it looks like students taking a bit more responsibility for themselves and their peers, not just their learning, but their enjoyment and their participation in class'. In approaching the teaching process, Fredrick explained that 'I've tried to be more deliberate in my planning and actions to integrate TPSR ... that would be the difference for me from a traditional PE program and the current approach I am taking'. He went on to discuss how, over time, TPSR became integrated into his regular process so that 'I would be making references to transfer and not have to be so conscious about doing it.' One observation recorded the following discussion in one of Fredrick's classes around the need for effort and demonstrated his attempt to develop the idea of transfer of learning.

So where else do you make an effort to see improvement ... in other classes good, now think about it first and then tell the person next to you where you think it could also be important in out of school situations.

Jessica explained how she was changing her instruction to give the students more responsibility: 'I think I'm trying to get them to ... take responsibility, for example, rather than dictating the warm-ups, I've been having them come up with some on their own'. Daisy explained that TPSR became such a part of her teaching practice that the students begin anticipating certain elements of the model. She recalled a time when she forgot to debrief at the end of the lesson and 'and the next minute the kids were saying it for me naturally ... [they talked about] self-direction and transfer without me having to prompt them'. Alicia gave an example of how she deliberately implemented the model into her regular teaching practice:

By saying soft defense in basketball, that instantly opens up a half a lesson ... [I can talk about the differences between] a competitive game and a social game ... it is developing to the point that I can literally just pull them out of my bag and start thinking that way.

\section{Struggling with traditional pedagogies}

Teaching with a TPSR approach requires teachers to give up some of the control over their classes, which can be uncomfortable. Some of the teachers in this study, particularly those such as Cynthia and Jessica who had been teaching for many years, noted that this was a challenge for them. Cynthia commented that:

the biggest challenge is that I've been teaching for a long time and as part of that you can get stale and not open to new ideas, and I think I sort of just felt comfortable in how I had been teaching.

Jessica explained that 'sometimes I felt like I was letting the control go, which can be a bit scary ... I was scared to try new things, and then other times I was unsure of how to scaffold the power over to the students'. On one occasion she commented that she had not 
slept the previous night as she was nervous about allowing students a choice of two warm up activities and did not know what would happen. By the end of the year observational notes recorded there had been a substantial change indicating a more complete implementation of the TPSR model:

Students were offered choices throughout and worked with full engagement. The final activity involved students deciding on what skill(s) they wanted to work on and then working at their own pace in groups. Jessica positioned herself away from the action and said she was available if anyone wanted help. One girl took advantage of the opportunity and spent time with Jessica working on her serve. What a change from the beginning.

In line with Curtner-Smith et al. (2008) notion of a watered down version of pedagogical model implementation, some of the teachers noted that they were interested in adopting some (but not all) elements of TPSR, or using the model only in specialised circumstances. Cynthia explained that she 'modified certain aspects of TPSR'. While she was reluctant to use the full version of TPSR, she 'tried to still keep the TPSR levels ... we have them on posters around the gym ... refer to them as vocab words'. Alicia felt as if the model was more appropriate for use in classes where children have behavioural issues. From her perspective, TPSR 'has a place within some programs more than others ... it worked well for Frederick's [class for students with behavioral issues], but for my regular class, I think they felt like I was treating them like babies, almost'.

Other teachers felt themselves slipping back into old teaching habits, particularly when the schedules got busy. These traditional practices were more automatic and required less planning. After beginning with a strong focus on TPSR, Harry lamented that 'I slipped back to my old habits, I suppose just going back to my normal teaching style ... you are just used to being in charge of your class and giving up control to the students is hard'. While Frederick wanted to implement the full version of the model, he noted that sometimes he felt himself retreating to traditional practices:

I think on those days when I've gone to class and I haven't done enough planning it's easy to resort back to your default settings, and I found that as some weeks went by and your workload is a little heavier, it's easy to go back to the things that are easier for you. It's taken conscious thought to do it well, and when I have consciously put time aside to plan with TPSR in mind it's worked really well.

\section{Background characteristics}

Participants discussed their acculturation as being focused on sport and involvement in physical activity. They also had positive things to say about their preservice training programs through professional socialisation. Some went on to discuss elements of their background that either served to introduce them to TPSR specifically, or helped make them more receptive to responsibility-focused instruction more generally.

\section{Teachers' acculturation and professional socialisation}

In concert with previous socialisation research (Curtner-Smith, 1997; Curtner-Smith et al., 2008) participants in this study described themselves as being involved in 'a lot of athletics' (Alicia). Frederick, for example, explained that he was a 'very active 
student [who] played a lot of different sports'. Ashley 'got on really well with PE teachers [in school]', and Harry 'had a strong interest in sport through high school and then that just carried on to university'. Ashley had fond memories of school-based $\mathrm{PE}$, recalling that 'I got on really well with my PE teachers and am friends with one from school days. I remember $[\mathrm{PE}]$ as being sport based, little structure and lots of activity'.

When talking about their teacher training programs, most of the participants spoke in general terms and highlighted the field-based nature of the program and their perception that the faculty were qualified, both of which are supported as best practices for teacher training (Richards et al., 2014). Ashley explained that there were 'long placements in the schools' and that 'basically, you learned on the job,' while Harry added that 'I think I learned most when I was actually putting the theory into practice, and I went to a lot of schools [during field-placements]'. Alicia added 'we had awesome lecturers at [my university]. They had taught for a significant amount of time and they hadn't been out of teaching long, so they knew what it was'. Cynthia explained that she really enjoyed her preservice teacher education program, recalling that 'I always got really good feedback when I was out on schools

... it seemed to suit my personality at the age that I was at ... it was one of the most brilliant years of my life'.

\section{Receptivity to responsibility}

Several of the teachers had either prior exposure to TPSR and/or were generally receptive to the idea of incorporating responsibility-based instruction into PE because of their past experiences. Daisy believed that she came into the CPD project with somewhat of an advantage because 'we obviously discussed it in a course at uni[versity] ... [so] I already knew a little about [TPSR] and I'd actually used it with a difficult class I had ... so I went into [the CPD] already knowing the basics'. Ashley observed that 'I always had an okay knowledge of Hellison's [TPSR], so there was a head start in there'. Cynthia did not learn about TPSR through her university training, but was exposed to it when 'I went to a PE conference in the 90s where Don Hellison ... did some teaching on what he called social responsibility in those days'.

While Alicia's exposure to TPSR was limited, she believed that teaching for social responsibility was important, particularly in relation to advocating for the discipline: 'as phys ed you get sick of other people pigeon holing you, that you are just a practical subject ... there are other [social] skills that you learn ... I feel like [TPSR] makes it a bit more obvious'. Jessica also believed in the importance of teaching social responsibility, noting that 'philosophically, respect for self, respect for other, working collegially and cooperatively, I think that's hugely important [for PE]'. Fredrick provided perhaps the clearest example of how his experience teaching in a school for at risk children helped him to see the relevance of TPSR:

For the first few months I was very teacher directed ... and it was just clearly not working, it was just a waste of time. So I refocused the way I was teaching and worked on some of their weaknesses with their interactions ... I would run PE sessions with them and try and teach them some personal skill, so that really helped me focus on that element and less about the PE ... that experience was quite influential for me. 


\section{Contextual facilitators of implementation}

Data analyses indicated that several socialisation factors operating in their current school contexts acted as facilitators to the implementation of TPSR. These facilitators included the alignment between TPSR and other educational initiatives, and social support that was facilitated through the CPD initiative.

\section{Alignment with educational and social initiatives}

During the time of TPSR implementation, the New Zealand government was promoting an initiative called Positive Behaviour for Learning (PB4L), which focused on 'explicitly teaching learning behaviors, rewarding students for positive behavior, and using restorative practices to repair relationships when there's been poor behavior' (Jamie). Several of the participants, such as Frederick, believed that TPSR 'aligns significantly with PB4L'. One teacher, Ashley, also observed how TPSR is 'aligned with the Maori improvement initiative, ki eke panuku, which is positive for connecting to our students'. This facilitated their implementation of TPSR, as the teachers were able to connect what they were doing in PE to larger initiatives. Daisy explained that '[TPSR] linked really well to achievement standard 1.1, which was looking at influences on students' participation ... [TPSR] worked quite positively [with that standard] because it gave them more to write about'. She explained that this 'increased my attention to TPSR'.

The connections between TPSR and PB4L allowed the PE teachers to connect their work to larger school structures in deeper, more meaningful ways. Frederick explained that the school 'principal is interested about the connections between TPSR and PB4L, so that's an area we've chatted about'. Ashley recalled that:

I've had two deans who have heard about what we're doing and they would like to start using it school wide ... they'd like to start using it as a basis for some of the behavior achievement objectives, particularly with year nine.

Alicia added that, because of the alignment, the school principal viewed TPSR as an opportunity for further integration of the departments at her school. She explained that 'our school is just on the cusp of looking at more integrated learned and de-siloing our departments ... [TPSR] will be able to help us further the mission of transfer from PE'. Finally, Ashley explained how his knowledge of TPSR, and the alignment it held with school initiatives, helped him receive a promotion:

The TPSR work gave me a number of practical stories that aligned with the PB4L initiative and they were really helpful to draw on at my interview as it showed I was able to implement this theoretical idea [PB4L] into my own teaching. I think it helped me get the promotion over some really experienced candidates.

\section{Professional development that embraces social support}

Several participants commented on how the TPSR CPD was implemented in a way that gave them multiple opportunities to connect with one another. The initial training at the start of the CPD program 'had a huge impact on my understanding because it was so good to just sit down with another PE department and go through what [TPSR] is actually going to look like' (Ashley). Even Cynthia, who was fairly critical of TPSR in general, appreciated that the CPD 'was good as a department... it was nice for us to be doing 
something together. All of the other CPD we do is school wide and not subject specific'. Several teachers were particularly excited about the opportunity for peer feedback. Alicia explained that 'Shelia already knew quite a bit from her university, so it was really helpful to watch her teach as I got used to using the model'.

Beyond the support provided through the CPD initiative, several of the teachers noted the importance of social support they provided one another on a more informal basis. This type of social support, which is indicative of a community of practice among teachers, has been found to be instrumental to teacher learning in previous research (Richards \& Templin, 2011). Daisy believed that it was important for the department to be on the same page and doing so helped to motivate her to use TPSR: if it wasn't a department thing I think I'd introduce [TPSR] anyway because I see the benefits, but I am not sure how much I would push myself. Fredrick was one of the department heads involved in the CPD initiative and he took a very deliberate approach to building social support among his teachers. He believed that:

We are very collaborative and share a lot of resources ... this has helped with TPSR ... The people who are not fully integrating it are definitely in the minority, but they are gradually being exposed to it ... gradually it'll become part of their process and hopefully they feel empowered to do it rather than forced to.

\section{Contextual inhibitors to implementation}

While there were several factors in the school settings that facilitated the implementation of TPSR, there were likewise those that acted as inhibitors. These were elements of the teachers' biographies and current organisational context that limited the extent to which TPSR was applied. Specific inhibitors included that TPSR can be a confusing model to implement, and that the teachers struggled with other priorities in the gymnasium.

\section{Implementation can be confusing}

Some of the teachers lamented that TPSR was a confusing pedagogical model to implement, particularly because they felt as if it was not accompanied by clear, straightforward teaching strategies. Unlike other models such as sport education (Siedentop, Hastie, \& van der Mars, 2004) and teaching games for understanding (Mitchell, Oslin, \& Griffin, 2006) that are accompanied by deliberate strategies for implementation, TPSR includes a loose framework with the expectation that teachers will take ownership to develop specific strategies to support the model goals (Hellison, 2011). For some teachers, this created a disconnection between theory and practice, which Fredrick discussed using the following analogy:

Sometimes [with TPSR] there's no right way of doing things, so it's like I am flying an airplane while trying to build it, and so that can be a challenge ... there are some teaching approaches, for example, Mosston's Spectrum of Teaching Styles, that have strategies and learning activities associated with them ... TPSR doesn't have that.

During her first interview early in the CPD initiative, Jessica noted that 'I think the real problem was that I was unsure how to implement it ... this looks great on paper, but how do I actually change my teaching strategies to get it going?'. This perceived lack of clarity led some teachers to feel as if it was difficult to implement the model, even if 
they agreed with its philosophical underpinning. Jessica made this point clear by explaining 'it's not as if I don't agree with those goals, but it is difficult to implement without having examples. I would like to see a few more examples to confirm my thinking'.

Cynthia had a difficult time understanding how TPSR differed from her typical teaching: 'you might do a TPSR activity which isn't any different than any other activity you might do in PE anyway, so how can you credit that to TPSR?' She went on to explain that this could have been clarified with more concrete examples by noting that 'regardless of how brilliantly anybody writes about anything academically, unless you can visualise how it works in practice it is a waste of my time because I won't understand how to do it'. In part, this helped to explain Cynthia's initial reluctance to implement the model. She explained that, at the beginning of the initiative, 'I didn't really know what I was doing and what I was supposed to be doing and I didn't seem to have much direction at all.' And it was just almost too hard sort of thing so Alicia added that her initial confusion was caused by the CPD providers 'sort of jump[ing] in with the assumption that we already know a little about [TPSR] ... I definitely was not using it in my own teaching [before], so I was getting really confused'.

\section{Other priorities in the gymnasium}

Some of the teachers struggled with the amount of time TPSR took away from physical activity in the gym. Daisy explained that the biggest challenge for her in implementing TPSR was 'probably not having enough time... I feel like there's a lot going on and you're talking about key vocab words you want to introduce... and then general content knowledge of sports, it's really hard to balance it all'. The disconnect between TPSR and traditional goals in PE was especially difficult for Cynthia, whose socialisation led her to be 'very conscious of giving [students] time on task and doing physical activity, and I find it frustrating to have to do a lot of talking and having them stop from moving to do evaluating and reflecting'. For her, the disconnect between TPSR and physical activity was something that was very difficult to reconcile:

I haven't come up with some decent ideas that allow maximum physical activity with the TPSR focus ... I just think about last term we were on fitness and ... when you give people choices they just don't complete as many tasks, whereas if I teacher lead the lesson the work gets done faster and more efficiently.

Beyond the tension between TPSR and physical activity, some of the teachers felt as if there were other school and governmental initiatives that got in the way of TPSR. Harry felt a great deal of pressure to implement the Collaborative Learners, Respectful Learners (CARE) program, which he described as 'a nationwide program a lot of schools are doing that relates to respecting the rights and feelings of others'. While there may have been some opportunities for this program to overlap with TPSR, Harry indicated that his focus on this initiative 'put me on the back foot [relative to TPSR] and I don't think I took up as much as I potentially could have ... in terms of day to day teaching, CARE would be number one'.

\section{Discussion and conclusions}

The purpose of this study was to examine the experiences of eight PE teachers involved in a long-term CPD initiative focus on TPSR in relation to their prior and ongoing 
socialisation. Results derived through qualitative data analysis indicated that, while many participants sought to be deliberate about implementing TPSR, several also struggled to relinquish traditional pedagogical approaches, and found themselves retreating to these approaches when they felt stressed or pressed for time. Further analyses indicated that socialisation factors in participants' backgrounds and current occupational settings influenced the ways in which they 'read' (Gore, 1990) the model. The socialisation experiences that drew the eight participants into the field of $\mathrm{PE}$, including positive experiences in school PE and involvement in youth sport and physical activity, were similar to those observed through previous OST research (Curtner-Smith, 2001; Curtner-Smith et al., 2008; Richards \& Templin, 2011). Several also described positive experiences in preservice teacher training programs that included quality indicators such as field experiences and qualified faculty members (Graber, 1996; Richards et al., 2014). Similar to previous research (Curtner-Smith et al., 2008; Vollmer \& Curtner-Smith, 2016) participants were more likely to be open to the implementation of TPSR when their prior experience included an overview of the model or experiences that helped them see its value (in this case, the value of responsibility pedagogy).

While background factors influence initial receptivity to TPSR, previous research has documented the role that school cultures play in determining the likelihood of modelsbased practice (Curtner-Smith et al., 2008). School cultures tend to operate as custodial bureaucracies that inhibit chance while promoting the status quo (Lawson, 1983; Richards et al., 2013). Such an environment can inhibit model-based practice (Curtner-Smith et al., 2008), especially in the case of something such as TPSR, which deviates from traditional, custodial views of PE. However, when innovative climates that promote collegiality and social support can be fostered, change is possible (Richards et al., 2014). The teachers in this study noted support in the form of well-structured, ongoing CPD as well as a departmental culture that embraced innovation and sought to empower teachers to take an active role in the change process. This environment, analogous to what has been described elsewhere as a community of practice (O'Sullivan, 2007; Richards \& Templin, 2011), can facilitate growth and serve as a positive catalyst for continued learning and change. The positive pressure for change may be compounded even more when teachers feel as if that change helps them to come into alignment with larger social structures. Teachers in the current study, for example, were able to recognise the connection between TPSR and larger school missions for responsibility.

While these types of communities can facilitate change, the individual dispositions of teachers involved in these contexts cannot be overlooked. Those teachers whose anticipatory and professional socialisation have led to the development of subjective theories (Grotjahn, 1991) that do not align with models-based instruction are likely to resist change even in the presence of supportive environments (Curtner-Smith et al., 2008; Vollmer \& Curtner-Smith, 2016). While this resistance can be covert and come in the form of strategic or feigned compliance with programing (Lacey, 1977), sometimes it is more overt and pronounced. This was observed in some of the teachers in the current study who rejected the notion of integrating responsibility into PE because they felt as if it would jeopardise physical activity time. It is, therefore, important for CPD provides and others working with preservice and inservice teachers to understand their starting point relatively to receptivity (Richards et al., 2013). Some teachers may not be ready for change. If that is 
the case, changes are more likely to be superficial than real, and traditional practices are likely to reemerge at the earliest convenience (Sparkes, 1991).

An additional inhibitor to change discussed in this study is the lack of clarity related to specific strategies for implementing TPSR. Unlike other models such as sport education (Siedentop et al., 2004) and teaching games for understanding (Mitchell et al., 2006) that are accompanied by deliberate strategies for implementation, TPSR includes a loose framework with the expectation that teachers will take ownership to develop specific strategies to support the model goals (Hellison, 2011). This led some teachers to a point of frustration because they did not know how to best teach the model. In a larger sense, the lack of clear teaching strategies could lead to 'toxic mutations' of TPSR whereby individuals develop hybrid and altered forms of the model that they call TPSR, but that deviate from the true spirit of the model. These mutations could threaten model fidelity beyond the work of individual teachers, and is something that the larger TPSR community may want to consider. The trick seems to be providing clear enough strategies to facilitate appropriate implementation without being so prescriptive as to threaten practitioners' ability to develop a sense of ownership and empowerment in their work.

The results of this study shed a great deal of light on the ways in which previous and current socialisation experiences influence teacher motivation to use, and fidelity to implement, TPSR. School cultures are critical in determining the likelihood of implementation. Specifically, in those environments in which administrators and senior members of the PE faculty discourage innovation, the implementation of models-based practice is unlikely (Curtner-Smith et al., 2008). However, even within innovative cultures, change is unlikely among teachers who embody a custodial orientation to teaching (Richards et al., 2014). Specifically, those who have no or limited exposure to the model during acculturation and professional socialisation, and those who hold a subjective theory (Grotjahn, 1991) of PE that does not include affective development, may be less likely to implement TPSR. Given the ways in which TPSR differs from many other pedagogical models in PE, developing an appreciation for and receptivity to responsibility-based instruction seems paramount. It is, therefore, critical that practitioners' voices be taken into consideration when developing interventions and CPD initiatives focused on TPSR. There are some teachers who are not comfortable with TPSR and it may not be the best pedagogical model for them to learn at that point in time. A model such as sport education, which deviates from teacher-driven, direct instruction, but maintain a central focus on sport (Curtner-Smith et al., 2008), may be a more appropriate alternative.

In conclusion, this study extends the literature related to ways in which socialisation experiences influence teachers' 'reading' of pedagogical models in PE. Both past socialisation experiences and those in the present structure of the school influenced teachers' receptivity to TPSR and the fidelity of model implementation. Future researchers should continue to examine the influence of socialisation on instruction in models such as TPSR, sport education, teaching games for understanding, and adventure education, which have already received attention in the literature. Additionally it is important that researchers examine models such as the skills themes approach, cooperative learning, and personalised system of instruction, which have not been studied through the lens of socialisation as of yet. Future research should take a multifaceted approach that incorporates fidelity checks of model implementation using systematic observation (Hemphill, Templin, et al., 2015; Wright, 2009). These fidelity checks can then be triangulated with 
teachers' perception of model implementation to provide a more detailed picture of how teachers implement the model.

\section{Disclosure statement}

No potential conflict of interest was reported by the authors.

\section{Notes on contributors}

K. Andrew R. Richards is an assistant professor in the Department of Kinesiology at the University of Alabama. His research focuses on teacher socialisation, with an emphasis on teacher stress and burnout, preservice PETE, marginalisation, and graduate student and faculty socialisation.

Barrie Gordon is a senior lecturer in the School of Education at Victoria University of Wellington. His research focuses broadly on teaching and learning in PE, with a specific focus on positive youth development through sport and physical activity contexts. He has worked extensively with the TPSR curricular model.

\section{References}

Beaudoin, S. (2012). Using responsibility-based strategies to empower in-service physical education and health teachers to learn and implement TPSR. Agora Para la Educación Física y el Deporte, 14, 161-177.

Blankenship, B. T., \& Coleman, M. M. (2009). An examination of 'wash out' and workplace conditions of beginning physical education teachers. Physical Educator, 66, 97-111.

Brown, D. (2005). An economy of gendered practices? Learning to teach physical education from the perspective of Pierre Boudieu's embedded sociology. Sport, Education and Society, 10, 3-23.

Casey, A. (2014). Models-based practice: Great white hope or white elephant? Physical Education and Sport Pedagogy, 19, 18-34.

Cassidy, T., \& Tinning, R. (2004). 'Slippage' is not a dirty word: Considering the usefulness of Giddens' notion of knowlegeability in understanding the possibilities for teacher education. Teacher Education, 15, 175-188.

Curtner-Smith, M. (1997). The impact of biography, teacher education, and organizational socialization on the perspectives and practices of first-year physical education teachers: Case studies of recruits with coaching orientations. Sport, Education and Society, 2, 73-94.

Curtner-Smith, M. (2001). The occupational socialization of a first-year physical education teacher with a teaching orientation. Sport, Education and Society, 6, 81-105.

Curtner-Smith, M., Hastie, P., \& Kinchin, G. D. (2008). Influence of occupational socialization on beginning teachers' interpretation and delivery of sport education. Sport, Education and Society, 13, 97-117.

Curtner-Smith, M., \& Sofo, S. (2004). Preservice teachers' conceptions of teaching within sport education and multi-activity units. Sport, Education and Society, 9, 347-377.

Escarti, A., Gutierrez, M., Pascual, C., \& Llopis, R. (2010). Implementation of the personal and social responsibility model to improve self-efficacy during physical education classes for primary school children. International Journal for Psychology \& Phschological Therapy, 10, 387-402.

Glaser, B. G., \& Strauss, A. (1967). The discovery of grounded theory: Strategies for qualitative research. Chicago, IL: Aldine.

Gordon, B. (2010). An examination of the responsibility model in a New Zealand secondary school physical education program. Journal of Teaching in Physical Education, 27, 138-154.

Gordon, B., \& Doyle, S. (2015). Teaching personal and social responsibility and transfer of learning: Opportunities and challenges for teachers and coaches. Journal of Teaching in Physical Education, 34, 152-161. 
Gordon, B., Jacobs, J. M., \& Wright, P. M. (2016). Social and emotional learning through a teaching personal and social responsibility-based after school program for disengaged middle school boys. Journal of Teaching in Physical Education, 35, 358-369.

Gore, J. (1990). Pedagogy as text in physical education teacher education: Beyond the preferred reading. In D. Kirk \& R. Tinning (Eds.), Physical education, curriculum and culture: Critical issues in the contemporary crisis (pp. 101-138). London: Falmer Press.

Graber, K. (1991). Studentship in preservice teacher education: A qualitative study of undergraduate students in physical education. Research Quarterly for Exercise and Sport, 62, 41-51.

Graber, K. (1996). Influencing student beliefs: The design of a 'high impact' teacher education program. Teaching and Teacher Education, 12, 451-466.

Grotjahn, R. (1991). The research programme subjective theories. Studies in Second Language Acquisition, 13, 187-214.

Hellison, D. (2011). Teaching responsibility through physical activity. Champaign, IL: Human Kinetics.

Hemphill, M. A., Richards, K. A. R., Gaudreault, K. L., \& Templin, T. J. (2015). Pre-service teacher perspectives of case-based learning in physical education teacher education. European Physical Education Review, 21, 432-450.

Hemphill, M. A., Templin, T. J., \& Wright, P. M. (2015). Implementation and outcomes of a responsibility-based continuing professional development protocol in physical education. Sport, Education and Society, 20, 398-419.

Jung, J., \& Wright, P. M. (2012). Application of Hellison's responsibility model in South Korea: A multiple case study of 'at-risk' middle school students in physical education. A'gora para la Educacio'n Fi'sica y el Deporte, 14(2), 140-160.

Kirk, D. (2013). Educational value and models-based practice in physical education. Educational Philosophy and Theory, 45, 973-986.

Lacey, C. (1977). The socialization of teachers. London: Methuen.

Larsson, H. (2014). Materialising bodies: There is nothing more material than a socially constructed body. Sport, Education and Society, 19, 637-651.

Lawson, H. A. (1983). Toward a model of teacher socialization in physical education: Entry into schools, teachers' role orientations, and longevity in teaching (part 2). Journal of Teaching in Physical Education, 3(1), 3-15.

Lawson, H. A. (1986). Occupational socialization and the design of teacher education programs. Journal of Teaching in Physical Education, 5, 107-116.

Lee, O., \& Choi, E. (2015). The influence of professional development on teachers' implementation of the teaching personal and social responsibility model. Journal of Teaching in Physical Education, 34, 603-625.

Lincoln, Y. S., \& Guba, E. (1985). Naturalistic Inquiry. New York, NY: Sage.

lisahunter. (2004). Bourdieu and the social space of the PE class: Reproduction of doxa through practice. Sport, Education and Society, 9, 175-192.

Lund, J., \& Tannehill, D. (2010). Standards-based physical education curriculum (2nd ed.). Sudbury, MA: Jones and Bartlett.

Lynn, S. K., \& Woods, A. M. (2010). Following the yellow brick road: A teacher's journey along the proverbial career path. Journal of Teaching in Physical Education, 29, 57-71.

Martinek, T., \& Hellison, D. (2009). Youth leadership in sport and physical education. New York, NY: Palgrave Macmillan.

Metzler, M. W. (2011). Instructional models in physical education (3rd ed.). Scottsdale, AZ: Holcomb Hathaway.

Mitchell, S. A., Oslin, J. L., \& Griffin, L. (2006). Teaching sport concepts and skills: A tactical games approach (2nd ed.). Champaign, IL: Human Kinetics.

Mrugala, M. W. (2002). Exploratory study of responsibility model practitioners (Unpublished doctoral dissertation). University of Illinois, Chicago.

O'Connor, A., \& Macdonald, D. (2002). Up close and personal on physical education teachers' identity: Is conflict an issue? Sport, Education and Society, 7(1), 37-54. 
O’Sullivan, M. (2007). Creating and sustaining communities of practice among physical education professionals. Journal of Physical Education New Zealand, 40, 10-18.

Pascual, C., Escartí, A., Llopis, R., Gutíerrez, M., Marín, D., \& Wright, P. M. (2011). Implementation fidelity of a program designed to promote personal and social responsibility through physical education. Research Quarterly for Exercise and Sport, 82, 499-511.

Patton, M. Q. (2015). Qualitative research and evaluation methods (4th ed.). Thousand Oaks, CA: Sage.

Pike, S., \& Fletcher, T. (2014). A review of research on physical education teacher socialization from 2000-2012. PHEnex Journal, 6(1), 1-17.

Richards, K. A. R., \& Gaudreault, K. L. (Eds.). (2017). Teacher socialization in physical education: New perspectives. Oxfordshire: Routledge.

Richards, K. A. R., \& Templin, T. J. (2011). The influence of a state mandated induction assistance program on the socialization of a beginning physical education teacher. Journal of Teaching in Physical Education, 30, 340-357.

Richards, K. A. R., Templin, T. J., \& Gaudreault, K. L. (2013). Understanding the realities of school life: Recommendations for the preparation of physical education teachers. Quest, 65, 442-457.

Richards, K. A. R., Templin, T. J., \& Graber, K. (2014). The socialization of teachers in physical education: Review and recommendations for future works. Kinesiology Review, 3, 113-134.

Schempp, P. G., \& Graber, K. (1992). Teacher socialization from a dialectical perspective: Pretraining through induction. Journal of Teaching in Physical Education, 11, 329-348.

Siedentop, D., Hastie, P. A., \& van der Mars, H. (2004). Complete guide to sport education. Champaign, IL: Human Kinetics.

Sparkes, A. (1991). Curriculum change: A gaining sense of perspective. In N. Armstrong \& A. Sparks (Eds.), Issues in physical education (pp. 1-19). London: Casell.

Stroot, S. A., \& Ko, B. (2006). Induction of beginning physical education teachers into the school setting. In D. Kirk, D. Macdonald, \& M. O'Sullivan (Eds.), The handbook of physical education (pp. 425-448). London: Sage.

Templin, T. J., \& Richards, K. A. R. (2014). C. H. McCloy lecture: Reflections on socialization into physical education: An intergenerational perspective. Research Quarterly for Exercise and Sport, 85, 431-445.

Templin, T. J., \& Schempp, P. G. (Eds.). (1989). Socialization into physical education: Learning to teach. Indianapolis, IN: Benchmark Press.

Tinning, R. (2004). Rethinking the preparation of HPE teachers: Ruminations on knowledge, identity, and ways of thinking. Asia-Pacific Journal of Teacher Education, 32, 241-253.

Tsangaridou, N., \& O'Sullivan, M. (1997). The role of reflection in shaping physical education teachers' educational values and practices. Journal of Teaching in Physical Education, 17, 2-25.

Valtonen, J., Reunamo, J., Hirvensalo, M., \& Ruismäki, H. (2015). Socialization into teaching physical education: Acculturative formation of perceived strengths. The European Journal of Social \& Behavioral Sciences, 12, 1683-1695.

Van Maanen, J., \& Schein, E. (1979). Toward a theory of organizational socialization. In B. Staw (Eds.), Research in organizational behavior (pp. 209-261). Greenwich, CT: JAI Press.

Vollmer, C. E., \& Curtner-Smith, M. (2016). Influence of acculturation and professional socialization on preservice teachers' interpretation and implementation of the teaching games for understanding model. The Physical Educator, 73, 74-96.

Wright, J. (2002). Physical education teacher education: Sites of progress or resistance. In D. Penny (Eds.), Gender \& physical education (pp. 190-207). London: Routledge.

Wright, P. M. (2009). Research on the teaching personal and social responsibility model: Is it really in the margins? In L. D. Housner, M. W. Metzler, P. G. Schempp, \& T. J. Templin (Eds.), Historic traditions and future directions on teaching and teacher education in physical education (pp. 290296). Morgantown, WV: Fitness Information Technology.

Wright, P. M., \& Burton, S. (2008). Implementation and outcomes of a responsibility-based physical activity program integrated into an intact high school physical education class. Journal of Teaching in Physical Education, 27, 138-154. 
Wright, P. M., \& Craig, M. W. (2011). Tool for assessing responsibility-based education (TARE): Instrument development, content validity, and inter-rater reliability. Measurement in Physical Education and Exercise Science, 15, 204-219.

Zmudy, M. H., Curtner-Smith, M., \& Steffen, J. P. (2009). Influence of occupational socialization on the practices and perspectives of two inexperienced adventure educators. Journal of Adventure Education \& Outdoor Learning, 9, 115-134. 